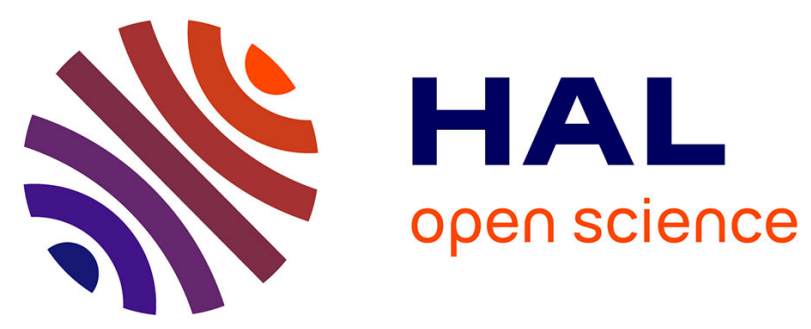

\title{
Pseudallicins A-D: Four Complex Ovalicin Derivatives from Pseudallescheria boydii SNB-CN85
} Jonathan Sorres, Charlotte Nirma, Véronique Eparvier, Didier Stien

\section{To cite this version:}

Jonathan Sorres, Charlotte Nirma, Véronique Eparvier, Didier Stien. Pseudallicins A-D: Four Complex Ovalicin Derivatives from Pseudallescheria boydii SNB-CN85. Organic Letters, 2017, 19 (15), pp.3978-3981. 10.1021/acs.orglett.7b01671 . hal-01590902

\section{HAL Id: hal-01590902 https://hal.sorbonne-universite.fr/hal-01590902}

Submitted on 20 Sep 2017

HAL is a multi-disciplinary open access archive for the deposit and dissemination of scientific research documents, whether they are published or not. The documents may come from teaching and research institutions in France or abroad, or from public or private research centers.
L'archive ouverte pluridisciplinaire HAL, est destinée au dépôt et à la diffusion de documents scientifiques de niveau recherche, publiés ou non, émanant des établissements d'enseignement et de recherche français ou étrangers, des laboratoires publics ou privés. 


\title{
Pseudallicins A-D, Four Complex Ovalicin Derivatives from Pseudal- lescheria boydii SNB-CN85
}

\author{
Jonathan Sorres,${ }^{\dagger}$ Charlotte Nirma, ${ }^{\dagger}$ Véronique Eparvier,,${ }^{\dagger}$ Didier Stien $*$,
}

${ }^{\dagger}$ CNRS, Institut de Chimie des Substances Naturelles UPR2301, Université Paris-Saclay, 91198 Gif-sur-Yvette, France.

*Sorbonne Universités, UPMC Univ Paris 06, CNRS, Laboratoire de Biodiversité et Biotechnologies Microbiennes (LBBM), Observatoire Océanologique, Banyuls-sur-Mer, France.

Supporting Information Placeholder

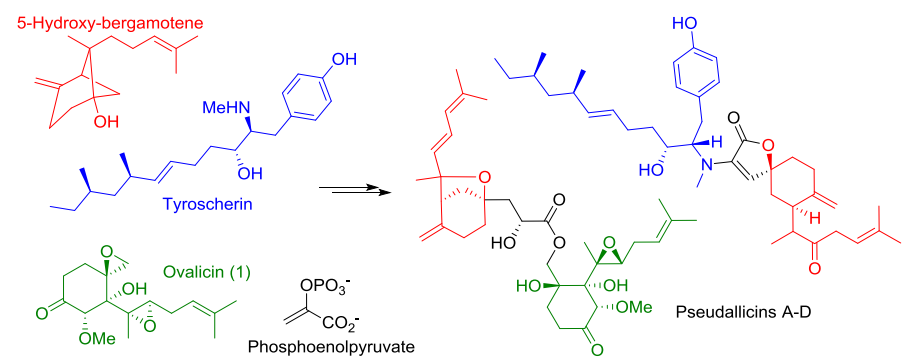

ABSTRACT: The isolation and complete structural elucidation of four complex ovalicin analogs, named pseudallicins A-D, from the fungus Pseudallescheria boydii strain SNB-CN85 are described. Based on structural similarities and information from the literature, a joint biosynthetic pathway for the pseudallicins is proposed.

As part of our investigation into the secondary metabolites produced by termite-born microbes, we examined the Pseudallescheria boydii strain SNB-CN85 isolated from the neotropical termite Termes cf. hispaniolae. This strain is closely related to SNB-CN73, another fungus isolated from Nasutitermes corniger. SNB-CN73 was shown to produce tyroscherin and $N$-methyl-tyroscherin, two antimicrobial metabolites which could explain the occurrence of Pseudallescheria strains in termites. ${ }^{1}$

We subjected the SNB-CN85 ethyl acetate extract to thorough chemical investigation. It was determined that the extract contained tyroscherin, similar to SNB-CN73, in the same relative and absolute configuration. ${ }^{1-3}$ It was observed that SNB-CN85 also contained ovalicin (1),${ }^{4}$ as well as several new ovalicin analogs, including 5-hydroxy-8-acetoxy-transbergamotene (2), ovalicin pseudo-dimers pseudallicins A (3) and B (4), and ovalicin-tyroscherin conjugates pseudallicins $C$ (5) and D (6) (Figure 1). Compound $\mathbf{2}$ is an acetylated analog of fungal metabolite 5,8-dihydroxy-trans-bergamotene. ${ }^{5,6} \mathrm{It}$ was converted into 5,8-dihydroxy-trans-bergamotene for comparison of analytical data. Details are provided in supporting information. In this study, we present the structural elucidation of compounds 3-6, and biosynthetic consideration regarding the novel ovalicin derivatives.

Pseudallicin A (3) and B (4) have the molecular formula $\mathrm{C}_{34} \mathrm{H}_{50} \mathrm{O}_{9}$, as deduced from the HR-ESI ${ }^{+}$-MS pseudomolecular ion at $\mathrm{m} / \mathrm{z}, 603.3541$ for 3 and $\mathrm{m} / \mathrm{z} 603.3554$ for 4 (calcd. 603.3528), requiring ten degrees of unsaturation. Upon analy-

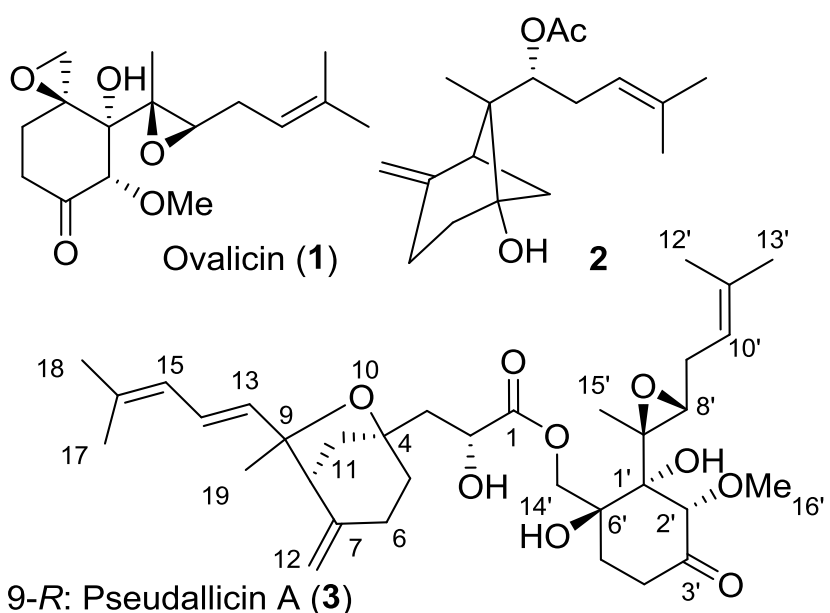

9-R: Pseudallicin A (3)

9-S: Pseudallicin B (4)

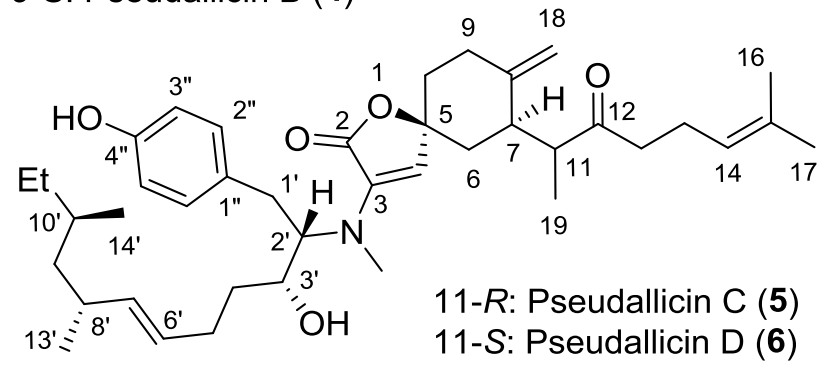

Figure 1. Secondary metabolites isolated from strain SNB-CN85 
Table 1. ${ }^{1} \mathrm{H}$ and ${ }^{13} \mathrm{C}$ NMR Data for Compounds 3-6 in $\mathrm{CD}_{3} \mathrm{OD}$

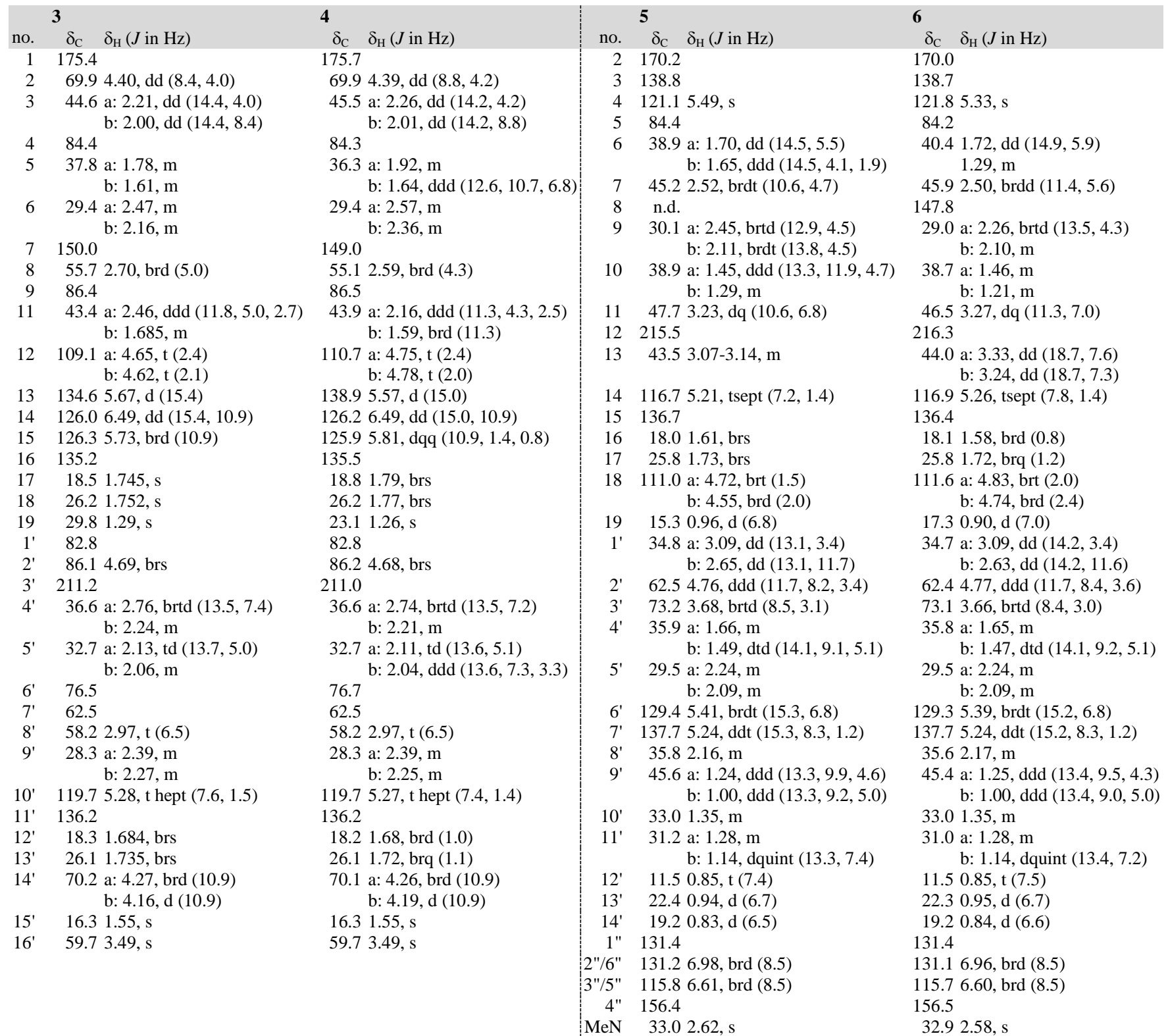

sis of the NMR data of compounds 3 and $\mathbf{4}$ (Table 1), one subunit of this compound was identified as an ovalicin moiety. Comparison of ${ }^{13} \mathrm{C}$ NMR chemical shifts with ovalicin is provided in supporting information (Tables S2-S3). The chemical shifts of carbons C-6' and C-14' at $\delta_{C} 76.5$ and 70.2, respectively, indicate that the ovalicin oxirane ring was opened. The ovalicine moiety is linked to an acyl group as evidenced by the $\mathrm{H}-14$ '/C-1 correlation in HMBC (Figure 2).

Within the acyl subunit, three spin systems were detected in the COSY experiment (Figure 2, bold bonds). These systems include a ${ }^{4} J$ coupling between $\mathrm{H}-5 \mathrm{a}$ and $\mathrm{H}-11 \mathrm{a}$. The connection of these systems with quaternary carbons was achieved by the detailed analysis of the HMBC spectrum. For example, the correlations H-3/C-1, C-2, C-4, and C-5 delineated a threecarbon linker between the ovalicin subunit and the bicyclic moiety. The six-membered ring was completed based on correlations of $\mathrm{H}-12 / \mathrm{C}-8, \mathrm{H}-6 \mathrm{~b} / \mathrm{C}-8$, and $\mathrm{H}-8 / \mathrm{C}-7$. $\mathrm{H}-8$ also correlated to $\mathrm{C}-9$, and $\mathrm{H}-19$ to $\mathrm{C}-8, \mathrm{C}-9$, and $\mathrm{C} 13$, defining the sequence C-8/C-9/C-13. Lastly, the chemical shifts of C-4 and C-9 at $\delta 84.4$ and 86.5 , respectively, indicated that these car- bons are linked to an oxygen. Based on the molecular formula, it is plausible that these carbons are interconnected by an oxygen bridge. This connection was later confirmed by the examination of NOE couplings within the bicyclic core of
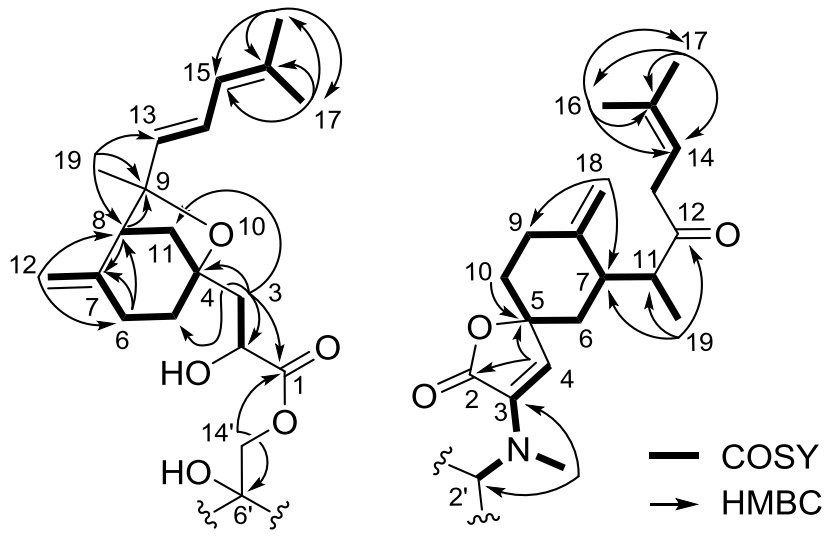

Figure 2. ${ }^{1} \mathrm{H}-{ }^{1} \mathrm{H}$ COSY and selected HMBC correlations of compounds $\mathbf{3}$ (left) and $\mathbf{5}$ (right) partial structures. 

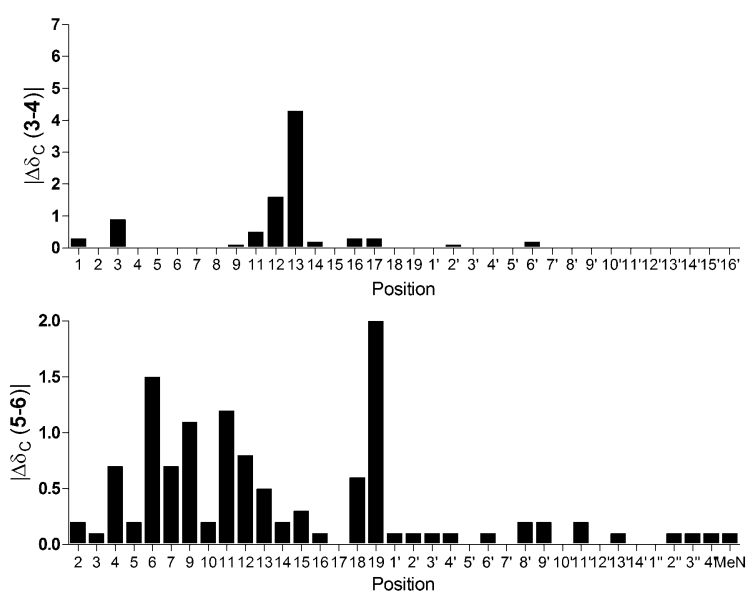

Figure 3. Absolute values of ${ }^{13} \mathrm{C}$ chemical shift difference between compounds $\mathbf{3}$ and $\mathbf{4}$ (up), and $\mathbf{5}$ and $\mathbf{6}$ (down).

both diastereoisomers $\mathbf{3}$ and $\mathbf{4}$. Indeed, compounds $\mathbf{3}$ and $\mathbf{4}$ are evidently closely related to each other, with very small variations in carbon chemical shifts (Figure 3). The main differences are on carbons $\mathrm{C}-13$ and $\mathrm{C}-19$, indicating that 3 and 4 are certainly diastereoisomers at $\mathrm{C}-9$. This finding was confirmed by NOE correlations H-13/H-6a and H-19/H11a in 3 and H-13/H11a and H-19/H-6a in 4. The stereogenic center C2 was characterized by conversion of compound $\mathbf{4}$ into the $(S)$ and $(R)$-Mosher esters (see supporting information). The chemical shift differences observed on protons $\mathrm{H}-3 \mathrm{a}$ and $\mathrm{H}-3 \mathrm{~b}$ in COSY established the $R$ configuration of C-2. Based on the differences in ${ }^{13} \mathrm{C}$ chemical shifts in this region (Figure 3 ), it is reasonable to postulate that $\mathrm{C}-2$ is also $R$ in compound 3 . The stereocenter $\mathrm{C}-8$ is defined by the proposed biosynthesis (Scheme 1), thereby allowing for the assignment of compounds 3 and 4 . These ovalicin analogs isolated from Pseudallescheria boydii have been given the trivial names pseudallicins $\mathrm{A}$ and $\mathrm{B}$.

Pseudallicin C (5) and D (6) have the molecular formula $\mathrm{C}_{39} \mathrm{H}_{57} \mathrm{NO}_{5}$, as deduced from the HR-ESI+-MS pseudomolecular ion at $\mathrm{m} / \mathrm{z}, 620.4313$ for $\mathbf{5}$ and $\mathrm{m} / \mathrm{z}, 620.4315$ for $\mathbf{6}$ (calcd. 620.4310 ), requiring twelve degrees of unsaturation. The examination of the NMR data allowed for the identification of a tyroscherin moiety. Comparison of the ${ }^{13} \mathrm{C}$ NMR spectra of tyroscherin with those of $\mathbf{5}$ and $\mathbf{6}$ is provided in supporting information (Tables S4-S5). The tyroscherin is linked to the other part of the molecule by the nitrogen, as evidenced by the long-range ${ }^{1} \mathrm{H}-{ }^{1} \mathrm{H}$ coupling $\mathrm{H}-4 / \mathrm{NMe}$ and the HMBC correlation NMe/C-3 (and also NMe/C-4 in 6, Figure 2). In addition to those involving the tyroscherin moiety, two spin systems were detected in the COSY experiment. The spiro carbon C-5 was established by the correlations $\mathrm{H}-4 / \mathrm{C}-5$ and $\mathrm{H}-10 \mathrm{~b} / \mathrm{C}-5$, and also $\mathrm{H}-4 / \mathrm{C}-10$ in 6 . The correlations of $\mathrm{H}-19$ with $\mathrm{C}-7, \mathrm{C}-$ 11 and $\mathrm{C}-12$ defined the sequence $\mathrm{C}-7 / \mathrm{C}-11 / \mathrm{C}-12$. Again, it was evident that $\mathbf{5}$ and $\mathbf{6}$ are diastereoisomers. The main difference in ${ }^{13} \mathrm{C}$ chemical shift is on $\mathrm{C}-19$ (Figure 3). It was possible to differentiate compounds 5 and $\mathbf{6}$ by comparative analysis of NOESY experiments (Figure 4).

The absolute stereochemistry at C-7 was defined as $R$ based on biosynthetic considerations (Scheme 1). The long-range Wcoupling $\mathrm{H}-6 \mathrm{~b} / \mathrm{H}-10 \mathrm{~b}$ in COSY indicated that these two protons are equatorial. $\mathrm{H}-7$ NOE with $\mathrm{H}-6 \mathrm{~b}$ and $\mathrm{H}-18 \mathrm{~b}$ indicated that H-7 should be equatorial in both 5 and $\mathbf{6}$, with the 6methyl-3-oxohept-5-en-2-yl side chain in the axial position. This finding was confirmed by the NOE correlation $\mathrm{H}-11 / \mathrm{H}-$ 9a. This correlation also indicates that $\mathrm{H}-11$ is directed towards the cyclohexane ring in both 5 and $\mathbf{6}$ with carbons 7 and 11 in an anti staggered conformation. In 5, H-19 correlated with the equatorial proton $\mathrm{H}-6 \mathrm{~b}$, while $\mathrm{H}-19$ correlated with $\mathrm{H}-18 \mathrm{~b}$ in $\mathbf{6}$. Taken together, these correlations established the C-11 configuration as $R$ in compound $\mathbf{5}$ and $S$ in $\mathbf{6}$. Finally, the absolute configuration of C-5 is $S$ in both compounds as proven by the NOE correlations of H-4 with H-6a and H-10a. Herein the compounds $\mathbf{5}$ and $\mathbf{6}$ are named pseudallicins $\mathrm{C}$ and D.

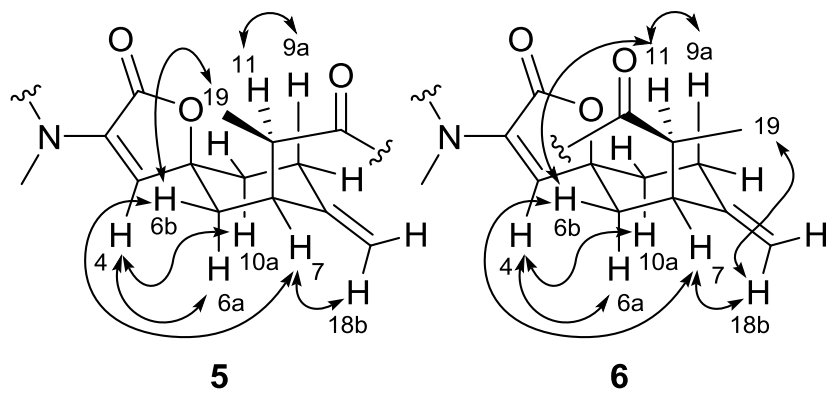

Figure 4. Selected NOE correlations in compounds 5 and 6.

The occurrence of these compounds in the same extract, as well as precedent literature on the biosynthesis of ovalicin, allowed for the proposal of a biosynthetic scheme for the pseudallicins. It has been demonstrated previously that the biosynthesis of ovalicin by the fungus Pseudeurotium ovalis involves stepwise 1,3-migration of the eight-carbon side chain of a bisabolyl cation generated by cyclization of farnesyl diphosphate. $^{7-9}$ In $P$. ovalis, the cyclisation is mediated by a bergamotene synthetase. ${ }^{10}$ Additionally, an analogous $\beta$-transbergamotene synthase has been characterized in Aspergillus fumigatus. ${ }^{11}$ In A. fumigatus, the fragmentation of the bergamotene four-membered ring occurs via the formation of a 5hydroxy-bergamotene intermediate, which undergoes oxidative cleavage of a carbon-carbon single bond mediated by a cytochrome P450 (7, Scheme 1). ${ }^{6}$ Interestingly, bergamotene analogs have been isolated in ovalicin-producing fungi, including in SNB-CN85.,12-13 The Grob fragmentation product $\mathbf{8}$ appears to be a close analog of the corresponding subunits in compounds 3-6. It can be postulated that the additional threecarbon chain is incorporated via an aldolisation with a phosphoenolpyruvate. Because carbon 9 in 3 and $\mathbf{4}$ (carbon 11 in $\mathbf{5}$ 6) is epimerized in the process and because an intermediate carbocation would account for the formation of all four compounds, the epoxide in $\mathbf{9}$ presumably opens to form a carbocation, which subsequently follows one of two paths. It can either be trapped by the hydroxyl group in C-4 to form the bicyclic core of $\mathbf{3}$ and $\mathbf{4}$ (Path A), or it can deprotonate to yield an enol and eventually a ketone in $\mathrm{C}-12$, as in compounds 5 and $\mathbf{6}$ (Path B). Compound $\mathbf{1 1}$ will then undergo a reduction of the carbonyl in C-2 and a $\beta$-elimination of the alcohol in C-10. The carboxylate $\mathbf{1 2}$ can incorporate ovalicin by nucleophilic substitution on the epoxide to form compounds $\mathbf{3}$ and $\mathbf{4}$. For compound 13, the formation of the lactone ring will generate a very electrophilic ketone that will react, probably spontaneously, with tyroscherin to yield $\mathbf{5}$ and $\mathbf{6}$.

On the one hand, this biosynthetic scheme is fully consistent with experimental evidence, i.e., the presence of 5-hydroxy-8- 
Scheme 1. Probable biosynthetic pathway to the pseudallicins

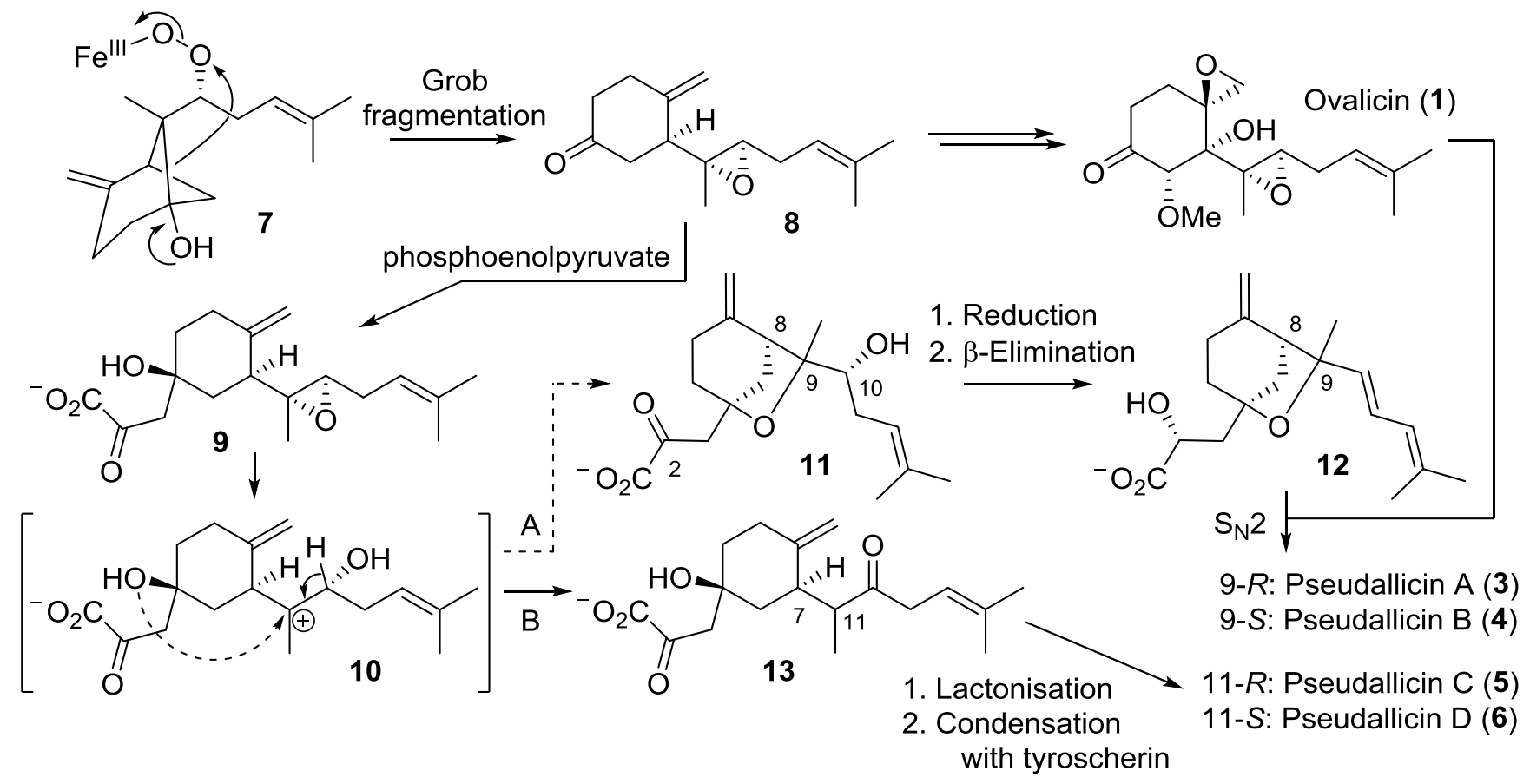

acetoxy-trans-bergamotene (2) and the occurrence of pseudallicins in the form of two couples of diastereoisomers. On the other hand, this scheme sheds light on the respective subunits' relative configurations.

In conclusion, compounds 3-6 are the first known dimers/conjugates of ovalicin. Also, Pseudallescheria strains are frequently associated with insects ${ }^{14}$ and can clearly be considered a rich source of novel and complex natural products. In our field work, six strains were isolated from different termite nests and will be investigated further. New developments will be reported in due course.

\section{ASSOCIATED CONTENT}

\section{Supporting Information}

The Supporting Information is available free of charge on the ACS Publications website.

Experimental procedures and full characterization data for compounds 2-6 (PDF).

\section{AUTHOR INFORMATION}

\section{Corresponding Author}

*(V. Eparvier) Tel: +33 1698236 79. E-mail:

veronique.eparvier@cnrs.fr.

*(D. Stien) Tel: +33 4301924 76. E- mail: didier.stien@cnrs.fr.

\section{ACKNOWLEDGMENT}

This work benefitted from an 'Investissement d'Avenir' grant managed by the Agence Nationale de la Recherche (CEBA, ref. ANR-10-LABX-25-01). The author gratefully acknowledge Prof. Reginaldo Constantino (University of Brasilia, Brazil) for termite identification.

\section{REFERENCES}

(1) Nirma, C.; Eparvier, V.; Stien, D. J. Nat. Prod. 2013, 76, 988.
(2) Katsuta, R.; Shibata, C.; Ishigami, K.; Watanabe, H.; Kitahara, T. Tetrahedron Lett. 2008, 49, 7042.

(3) Tae, H. S.; Hines, J.; Schneekloth, A. R.; Crews, C. M. Org. Lett. 2010, 12, 4308.

(4) Sigg, H. P.; Weber, H. P. Helv. Chim. Acta 1968, 51, 1395.

(5) Zhang, P.; Bao, Q.; Dang, H. T.; Hong, J.; Lee, H. J.; Yoo, E. S.; Bae, K. S.; Jung, J. H. J. Nat. Prod. 2009, 72, 270.

(6) Lin, H.; Tsunematsu, Y.; Dhingra, S.; Xu, W.; Fukutomi, M.; Chooi, Y.; Cane, D. E.; Calvo, A. M.; Watanabe, K.; Tang, Y. J. Am. Chem. Soc. 2014, 136, 4426.

(7) Tanabe, M.; Suzuki, K. T. Tetrahedron Lett. 1974, No. 49 , 4417.

(8) Cane, D. E.; Levin, R. H. J. Am. Chem. Soc. 1975, 97, 1282.

(9) Cane, D. E.; Levin, R. H. J. Am. Chem. Soc. 1976, 98, 1183.

(10) Cane, D. E.; Mcllwaine, D. B.; Harrison, P. H. M. J. Am. Chem. Soc. 1989, 111, 1152.

(11) Lin, H.; Chooi, Y.; Dhingra, S.; Xu, W.; Calvo, A. M.; Tang, Y. J. Am. Chem. Soc. 2013, 135, 4616.

(12) Cane, D. E.; King, G. G. S. Tetrahedron Lett. 1976, 4737.

(13) Cane, D. E.; McIlwaine, D. B.; Oliver, J. S. J. Am. Chem. Soc. 1990, $112,1285$.

(14) Wu, Q.; Jiang, N.; Bo Han, W.; Ning Mei, Y.; Ming Ge, H.; Kai Guo, Z.; Seik Weng, N.; Xiang Tan, R. Org. Biomol. Chem. 2014, 12, 9405 . 